(2) Open Access Full Text Article

METHODOLOGY

\title{
Improved centration of the type I Boston Keratoprosthesis in donor carrier tissue
}

This article was published in the following Dove Press journal:

Clinical Ophthalmology

16 August 2010

Number of times this article has been viewed

\author{
Yousuf M Khalifa' \\ Majid Moshirfar ${ }^{2}$ \\ 'Flaum Eye Institute, University \\ of Rochester, Rochester, NY, USA; \\ ${ }^{2}$ Moran Eye Center, University of \\ Utah, Salt Lake City, UT, USA
}

Correspondence: Majid Moshirfar 65 Mario Capecchi Way, Salt Lake City, UT 84 I32, USA

$\mathrm{Tel}+\mid$ 80I 58I 2352

Fax +l 80I 58I 3357

Email majid.moshirfar@hsc.utah.edu

\begin{abstract}
The type 1 Boston Keratoprosthesis preparation requires a 3-mm central punch and an $8.5 \mathrm{~mm}$ or larger punch in the carrier tissue. These punches are ideally concentric, but we have found difficulty in achieving concentric punches when the larger punch is performed first. We present a modification in the preparation procedure to help minimize centration error.
\end{abstract}

Keywords: Boston Keratoprosthesis, centration error

\section{To the editor}

The type 1 Boston Keratoprosthesis (KPro) is a poly (methyl methacrylate) device that has gained acceptance in many types of end-stage corneal diseases as a viable surgical option. ${ }^{1-3}$ The KPro is assembled using a carrier donor tissue, and its optics afford excellent visual acuity and field of vision ${ }^{4}$ assuming that the alignment of the KPro is optimized. Centration of the KPro is determined during preparation of the donor carrier tissue and host trephination. The manufacturer's recommended steps for KPro preparation involve punching the donor with an $8.5 \mathrm{~mm}$ or greater diameter followed by a 3-mm central punch. We have found that centration of the KPro in the carrier tissue can be difficult using this procedure, and we present a modification for minimizing centration error.

\section{Technique description}

The center of the donor carrier tissue is marked using a surgical marker, and a 3-mm central punch is performed using the centration mark (Figure 1A). The accuracy requirement of centration in this step is not stringent. The 3-mm-diameter punched tissue is removed, and the edge is inspected. An appropriate outer diameter punch size is selected, which should be at least $8.5 \mathrm{~mm}$ diameter if possible, and a disposable Barron corneal punch (Katena Eye Instruments, Denville, NJ) is typically used. The donor carrier tissue is placed on the punch block and the 3-mm hole is centered between the vacuum holes of the punch block (Figure 1B), and the vacuum is engaged. The punch is then carefully performed, and the KPro is assembled and sutured to the host rim (Figure 1C).

\section{Discussion}

The type 1 Boston KPro is a viable therapeutic option for many end-stage corneal diseases that are poor candidates for traditional penetrating keratoplasty, and the 

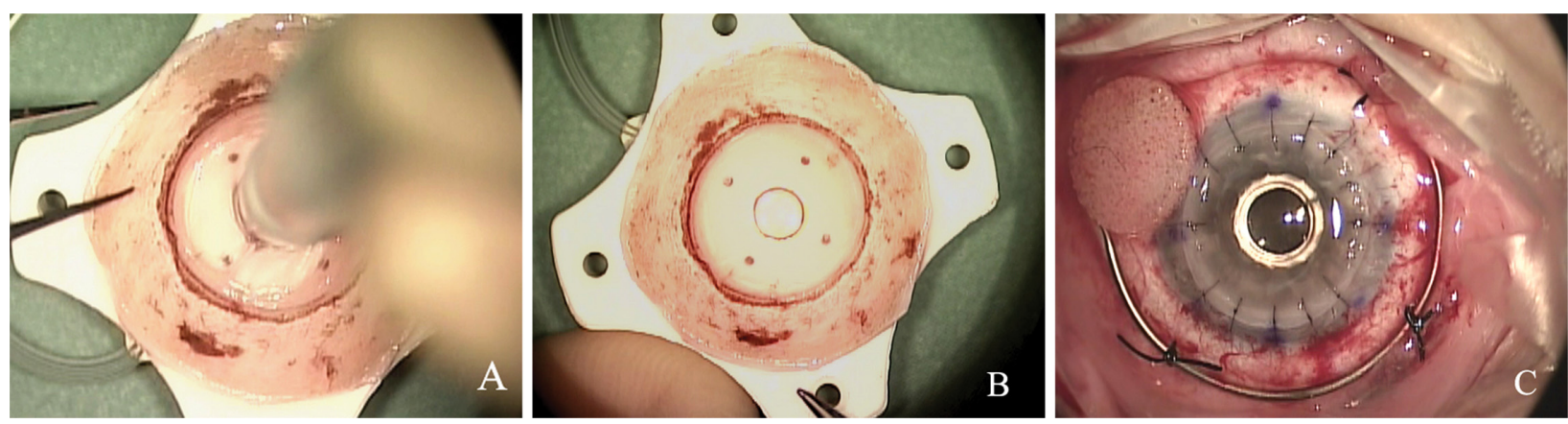

Figure I Preparation of the carrier tissue with a 3-mm dermatologic punch first $(\mathbf{A})$. The 3-mm hole is then centered between the vacuum ports of the punch block to create 2 concentric punches (B). The keratoprosthesis optic is perfectly centered in the carrier tissue, minimizing scatter and other optical phenomena and allowing for easier suturing and better tension distribution (C).

reported visual results of the KPro have been good. ${ }^{2,3}$ The assembly of the KPro involves preparation of a carrier tissue with two punches that are ideally concentric. The manufacturer recommends punching the outer circle first and then the central 3-mm punch. We have found difficulty in creating concentric punches using this technique (Figure 2), and we believe that punching the central 3-mm hole first and then using this hole to center within the Barron corneal punch's four vacuum ports affords much better control. If the manufacturer's recommendations are followed and the outer punch is performed first, then the free-hand 3-mm dermatologic punch must be placed perfectly for a concentric result.

The optical performance of the KPro on an optical bench using a 3-mm pupil and precise alignment was evaluated and found to produce a sharp, crisp image with a tight point-spread function. ${ }^{4}$ The optical cylinder, under these optimized alignment conditions, produced scattered ghost images when the 3-mm pupil was widened to $10 \mathrm{~mm}$. If the alignment of the KPro is suboptimal with the cylinder off-axis from the fovea, then the projected image will most likely be further degraded. We believe the centration of the KPro in the donor carrier and host cornea is integral for optimal alignment of the cylinder and minimization of scatter and other optical phenomena. Our technique of punching the 3-mm inner hole first and then centering the outer punch on this hole relieves much centration uncertainty in KPro preparation. In addition to the optical advantages of optimizing centration, suturing to the host rim is much easier with better distribution of tension when the KPro is centered. We have not found any limitations or problems from this simple modification of Kpro assembly.

\section{Disclosure}

The authors report no conflicts of interest in this work.
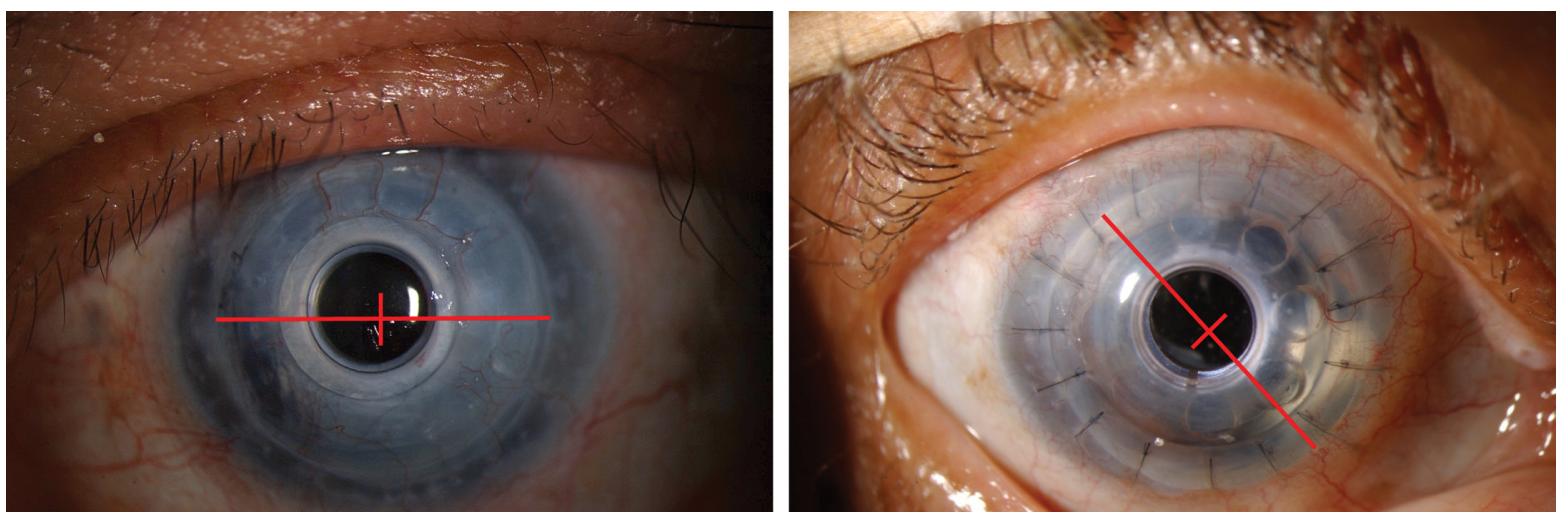

Figure 2 Examples of type I Boston Keratoprosthesis when prepared with the outer punch first and then the 3-mm central punch. Centration measurements show that the keratoprosthesis optic is poorly centered in the donor tissue. 


\section{References}

1. Dohlman CH. Background of the present Boston Kpro I for graft failures. Boston Keratoprosthesis Update. 2004;1:1-2.

2. Zerbe BL, Belin MW, Ciolino JB; Boston Type 1 Keratoprosthesis Study Group. Results from the multicenter Boston Type 1 Keratoprosthesis Study. Ophthalmology. 2006;113:1779-1784.
3. Bradley JC, Hernandez EG, Schwab IR, Mannis MJ. Boston Type 1 Keratoprosthesis: the University of California Davis experience. Cornea. 2009;28:321-327.

4. Sayegh RR, Avena Diaz L, Vargas-Martin F, Webb RH, Dohlman CH, Peli E. Optical functional properties of the Boston Keratoprosthesis. Invest Ophthalmol Vis Sci. 2010;51(2):857-863.

\section{Publish your work in this journal}

Clinical Ophthalmology is an international, peer-reviewed journal covering all subspecialties within ophthalmology. Key topics include: Optometry; Visual science; Pharmacology and drug therapy in eye diseases; Basic Sciences; Primary and Secondary eye care; Patient Safety and Quality of Care Improvements. This journal is indexed on

Submit your manuscript here: http://www.dovepress.com/clinical-ophthalmology-journal

\section{Dovepress}

PubMed Central and CAS, and is the official journal of The Society of Clinical Ophthalmology (SCO). The manuscript management system is completely online and includes a very quick and fair peer-review system, which is all easy to use. Visit http://www.dovepress.com/ testimonials.php to read real quotes from published authors. 